\title{
Global Chemical Leasing Award 2010
}

\author{
Thomas Jakl \\ Director Chemicals Policy Unit, V/2 Federal Ministry for the Agriculture, Forestry, \\ Environment and Water Management, Wien, Austria \\ E-mail: thomas.jakl@lebensministerium.at \\ Received September 16, 2010; revised October 14, 2010; accepted November 24, 2010
}

\begin{abstract}
The Global Chemical Leasing Award was presented for the first time in March 2010 to organizations, companies and individuals for their outstanding efforts to enhance the visibility of Chemical Leasing around the world and reward successful Chemical Leasing initiatives and implementation. Chemical Leasing is the new business model in the field of sound use of chemicals, initiated and subsidized by the Austrian Federal Ministry for Agriculture, Forestry, the Environment and Water Management and jointly promoted with UNIDO. The decisive new aspect of this business model, which distinguishes itself from the traditional supplier-user relation, is to make the service performed by the chemical substance the basis of payment for the business operation, e.g. according to cleaned area, treated number of pieces, or performed hours of operation (= unit of payment). In this way an efficient use of chemicals is in the interest of all parties involved. The award was jointly organized by UNIDO and the Austrian Federal Ministry for Agriculture, Forestry, the Environment and Water Management. Organizations, companies and individuals worldwide were able to take part in the competition. The cases of the winners are described in detail and show the applicability of Chemical Leasing to the different industrial processes. Among these are water clarification and oil dehydration in Colombia, mineral water and beverage production in Serbia, oil \& gas exploration and production and specifically deep gas field development projects in different places, industrial cleaning with solvents in Austria and textile dyeing in India.
\end{abstract}

Keywords: Chemical Leasing, Award, Business, Industry, Model, Environment, Unido, Austrian Environment Ministry

\section{Introduction}

"Chemical Leasing" ("ChL”) is the new business model in the field of commercial use of chemicals, initiated, promoted and subsidized by the Austrian Environment Ministry ("Lebensministerium"). The decisive new aspect of this business model, which distinguishes itself also from the traditional supplier-user relation, is to make the service performed by the chemical substance the basis of the business operation. This service, e.g. solving, cleaning, lubricating etc. comes to the fore, and becomes also the calculation basis. The payment is no longer made according to the sold quantity of chemicals, but e.g. according to cleaned area, treated number of pieces, or performed hours of operation (= unit of payment). In this way an efficient use of chemicals is in the interest of all parties involved.

Due to this service-oriented cooperation between a chemicals supplier and a chemicals user the material throughput is reduced and saving potentials, such as resources, costs, workload, and reduction of emissions are being realised.

As this new business model also embraces the usephase of a chemical product, the focus on "sales volumes" is abandoned in favour of service-oriented performance.

On average, the companies adopting the new business model can expect a reduction in costs, primarily resulting from efficiency gains. However, the chemical suppliers will also be able to benefit from this situation, because they can integrate their process-related know-how in a profitable way.

This new model results in economic as well as ecological advantages and the argument that environmental protection causes in principle additional costs is thus invalidated while leading to a classical "win-win" situation.

Fair distribution of the savings generated and a clear legal contract design are prerequisites for the success of the business model. 
Some elements of Chemical Leasing also exist in other service-oriented business strategies (e.g. chemical management services, single source supply), but the "cost per functional unit - approach", process optimization and quality control related to environmental performance, is usually a distinctive feature of Chemical Leasing. In addition to that Chemical Leasing is not only an innovative business model, but also supports the objectives of many national, regional and international environmental and economic policy regulations and programmes.

\section{Preferred Segments of Industry}

For Austria studies have shown that by means of such a business model a reduction of use of up to 53,000 tonnes of chemicals can be achieved, which corresponds to about one third of the overall quantity used by the relevant companies. In the field of commercial use of chemicals some industrial applications, such as cleaning/degreasing, etching, casting, cooling/lubricating, as well as chemical synthesis (catalysts) and water conditioning, are particularly appropriate for the introduction of a ChL model.

In cooperation with the United Nations Industrial Development Organisation UNIDO and its 47 National Cleaner Production Centres (NCPCs), and with the support of the Austrian government international projects were initiated in 2005 in Mexico, Egypt, and Russia. Three years later projects followed in Colombia, Morocco, Serbia and Sri Lanka. In addition, the German government also joined and supported this global undertaking in 2008.

\section{The Global Chemical Leasing Award [2-4]}

The successful ChL projects, which could be realised in cooperation with UNIDO, have caused reflections, on the one hand on how this business model could be even spread further, and on the other hand on how one could acquire knowledge about ChL applications already existing on a global scale.

For this purpose the Federal Ministry of Agriculture, Forestry, Environment and Water Management and UNIDO launched in September 2009 the Global Chemical Leasing Award. This award is the first of its kind and should contribute to the "greening" of industry and promote safer chemicals management.

\subsection{Facts and Figures of the Award}

The Global Chemical Leasing Award is open to organisations, companies and individuals worldwide and comprises 4 categories. The evaluation criteria were evaluated on a $0-4$ scale ( 0 - insufficient and 4 - excellent) and multiplied by a defined weighting factor (WF). For the total category score all activities within one category were added. Only activities that exceed the minimum score of 2.5 were considered for nomination.

The final award ceremony took place on March 1, 2010 in Prague within the frame of the international CHEMCON Conference. The first place winner in each category received prize money of USD 5,000. The jury consisted of six members that have profound understanding of Chemical Leasing strategies as well as first- hand experience with implementation and promotion practices.

In total 27 award applications were reviewed.

\subsection{The Winners}

Special Award for Outstanding Efforts in Implementing Chemical Leasing in the Supply Chain was given to IKEA India.

In Category 3: scientific publications.

No application obtained the minimum of 2.5 points to

\begin{tabular}{ccc}
\hline & Category 1 - Case Studies & Bronze \\
Ecopetrol, Colombia & Silver & Safechem Europe, Germany \\
Cabot Specialty Fluids, UK & Bronze \\
Gold & Ecolab, Serbia + Knasz Milos, Serbia & Mr. Ali Abo Sena, NCPC Egypt \\
Mr. Yuan Kuan, NCPC & Silver & \\
Colombia & Mr. Juneja Naveen, \\
& DNA Expert Services, \\
& India & Silver \\
Gold & Category $\mathbf{4}$ - Public relation & \\
Mr. Anurag Priyadarshi, IKEA Trading HK, India & Chemical Strategic Partnership, \\
Ms. Vojislavka Satric, NCPC - Serbia & Ms. Jill Kaufmann, USA & \\
\hline
\end{tabular}


qualify for successful submission.

\section{In the Following Section the Cases of the Winners in the Category "Case Studies" Will Be Described in Detail}

\subsection{Winner Case Ecopetrol SA and Partner Nalco SA, Columbia}

Industrial process: water clarification and oil dehydration in Castilla plant.

Ecopetrol S. A: It is the country's largest company and the main producer of petrol in Colombia. It ranges among the top 40 oil companies in the world and the five largest oil companies in Latin America. Ecopetrol exploits hydrocarbon extraction fields all over Colombia and operates two refineries and a pipeline network of $8,500 \mathrm{~km}$. In 2003 it became a publicly traded company and initiated a transformation process to achieve higher financial autonomy and competitiveness.

Nalco SA: it is the chemicals supplier, one of the world leaders in water treatment and process improvement applications, providing services, chemicals and equipment to industrial and institutional customers. The global corporate and research headquarters are located in Sugarland, Texas. Nalco's approximately 10,500 employees work with more than 60,000 customers in around 130 countries.

Both, user and provider, worked together with the National Cleaner Production Centre - Colombia and UNIDO to achieve the business model. Before Chemical Leasing was applied, Castilla plant received $352 \mathrm{kbbl}$ (kilo barrel) of oil and water, which were treated with 15.14 barrels of chemicals. Since the evaporation of water caused a loss of $1,718 \mathrm{bls}$, the plant produced a total of $72 \mathrm{kbbl}$ of oil, $279 \mathrm{kbbl}$ of water and 107 bls of solid waste. The unit of payment was gallons/kilos of chemicals used in each field.

After Chemical Leasing, Castilla plant extracted and treated $434 \mathrm{kbbl}$ of oil and water, using 14.88 barrels of chemicals. As water evaporation accounted for a loss of $1785 \mathrm{bls}$, the plant produced a total of $91 \mathrm{kbbl}$ of oil, 343 $\mathrm{kbbl}$ of water and $106 \mathrm{bls}$ of solid waste. These data have shown that more oil and water is treated with fewer chemicals. The new unit of payment is USD per kilo barrel of oil with the specified quality.

Some benefits achieved:

- Avoid the damage associated with the chemical wastes in the process.

- Simplify the operation logistics by injecting just one product.

- Measurement of the water quality parameters in real time.

- Risk reduction.

- Social benefits and better working conditions
- Reduction of the costs of the treatment process by almost 20\%.

- Reduction of the environmental impact of the water and oil treatment.

\subsection{Winner Case Knaz Milos and Partner Eco- lab Hygiene, Serbia}

Industrial process: mineral waters and beverage production

Knjaz Milos is the biggest producer of mineral water and beverages in the Republic of Serbia and was founded in 1811 . The annual production capacity amounts to 300 million litres of beverages. In 2008, 220 million litres of mineral water and beverages were produced. The company has about 900 employees and is certified according to ISO 9001, ISO 14001 and ISO 22000.

Ecolab is the global leader in cleaning, sanitising, food safety and infection prevention products and services with sales of USD 6 billion and more than 26,000 associates. They deliver comprehensive programmes and services to foodservice, food and beverage processing, healthcare, and hospitality markets in more than 160 countries. The company is certified according to ISO 9001/14001 and EN 46001 (for medical devices).

To ensure the smooth movement of the bottles down a packaging conveyor, the conveyor belt has to be lubricated. Before Chemical Leasing, Knjaz Milos used a lubricant which was dissolved in water. It had to be microbiologically effective to prevent the natural growth of microbes in this favourable environment and was sprayed onto the conveyor through nozzles.

The chemical used as a lubricant has hazardous properties. It causes eye and skin irritation and is toxic to aquatic organisms. It may cause long-term adverse effects in the aquatic environment. The annual consumption for the lubrication of one conveyor (which is now the subject of the Chemical Leasing contract) amounted to $6,000 \mathrm{~kg}$ of lubricant.

For water pre-treatment sodium hypochlorite is used. This chemical also has hazardous properties. In contact with acids it releases toxic gas, causes burns and is very toxic to aquatic organisms. Every year, 270 litres of sodium hypochlorite were used for water pre-treatment on this packaging line. As the chemical had to be dissolved in water, waste water $\left(1,500 \mathrm{~m}^{3}\right.$ per year) was contaminated with hazardous chemicals.

Due to foam overflow (the lubricant is surface active), potential problems with occupational safety arose because the floor was slippery. The unit of payment was the amount of chemicals sold (litres or kilograms).

During the implementation of the ChL business model, the process was modified and the chemical was substituted by a non-hazardous one. In addition, new equip- 
ment was installed (dosage system, spraying nozzles). Due to these changes, the process has been significantly improved, since almost no bottles fall off the conveyor belt any more. This fact is very important in high season when Ecolab works seven days a week in two shifts.

The efficiency of the line has been increased (which is one of the key performance indicators in Knjaz Milos) and the working life of the conveyor has been significantly extended. The downtime which was about 15 minutes per shift before the implementation of the ChL model was eliminated and the costs of packaging can now be precisely calculated and predicted.

The health and safety of workers significantly improved due to reduced quantity of aerosols in the air, cleaner working environment and less risk of injuries as the floor is no longer slippery. The new unit of payment is the number of working hours of the conveyor.

The costs of packaging connected with conveyor work were $€ 14,700$ per year, including water, water pre-treatment, water treatment and the chemical for 5,000 working hours.

After the ChL model implementation, costs for the same working period have been reduced to $€$ 9,000 (total savings are $€ 5,700$ ).

By this contract one PET packaging line is covered. As the first results are very encouraging, Ecolab already plans to implement the $\mathrm{ChL}$ model on the other PET packaging lines.

Some benefits achieved:

- In this case the process was modified and the chemical was substituted by a non hazardous and ecofriendly one: Sodium hypochlorite is no longer used for water pre-treatment so the consumption of active chlorine is reduced by $7.5 \mathrm{~kg}$ per year, which means about 2,70 l of sodium hypochlorite.

- The consumption of the chemical for lubrication is around three times less than before Chemical Leasing.

- Water is no longer used for the process, resulting in a reduction of consumption by $1,500 \mathrm{~m}^{3}$ per year.

- The consumption of chemicals for waste water treatment is reduced.

- Reduced quantity of aerosols in the air.

- Higher cleaning standards - Microbiological problems are eliminated since water is no longer used.

\subsection{Winner Case Cabot Specialty Fluids Ltd UK and Contract Partners Statoil, Shell, BP, ExxonMobil and Total}

Industrial process: oil \& gas exploration and production sector and specifically deep gas field development projects.
Cabot Specialty Fluids (CSF) is the world's leading producer of cesium formate brines for the oil and gas industry. The chemicals provided on lease are cesium formate and blends of potassium formate and cesium formate dissolved in water to make "formate brines". Formate brines of this type are used as well construction and intervention fluids, especially in challenging deep gas field developments. Formate brines are used to assist the drilling, completion, and maintenance of these deep wells (usually offshore).

The main partners are the major oil companies including Statoil, Shell, BP, ExxonMobil and Total. The traditional chemical company strategy for supplying chemicals to the oil E\&P industry is for the vendors to sell their products directly to the oil companies on a no-return basis. For a typical well construction this means that maybe 500 tonnes of chemicals are deployed in creating a drilling and completion fluid for one operation and losses of $>100$ tonnes of chemicals to the environment during use are possible. The residual chemicals have to be disposed as waste at the end of the well construction operation.

In 1996 CSF started with a new Chemical Leasing model: The contract partners lease cesium formate brine from CSF for the duration of a particular phase of a well construction job that might last typically 30-60 days. Certain other operations like well suspensions can require a lease of up to 2 years. CSF charges the oil companies a leasing fee based on the days the product is in the field, plus a charge for any losses (typically 10-15\%) of the product during use and reclamation. On completion of the operation the oil company returns the chemical to CSF for reclamation. The special innovative characteristic of this case study is the leasing of a very highvalue chemical as an aqueous solution. Under this scheme CSF retains ownership and stewardship of the chemical at all times.

CSF has leased cesium formate brine to $>220$ well construction operations around the world in the past 10 years.

The classic use of cesium formate brine is as a safe replacement of zinc bromide brine (a hazardous chemical classified as a priority marine pollutant).

CSF's largest client has leased cesium formate brine for $>50$ well construction operations in the North Sea over the past 10 years. Typical lease value is in the range \$ 1-2 million per individual job (per deployment of chemical).

This business model is a complete break with the traditional one-way-sale (no return) business model used by chemicals suppliers to the oil industry for the past 80 years.

Instead of paying \$ 6 million for the chemical under a 
direct sale agreement the oil company only pays typically \$1-2 million per job by leasing from Cabot.

The provision of a high-value product like cesium formate brine on leasing terms encourages the oil companies to undertake their projects as efficiently as possible while reducing waste and environmental discharges to the absolute minimum.

The eco-efficiency and economics of leasing cesium formate brines to the oil industry have been studied in detail by two independent consultancies, namely Gaia Consulting of Finland and BASF of Ludwigshafen

BASF conducted an eco-efficiency analysis on CSF's leasing of cesium formate brine and found that it was more sustainable and eco-efficient than the traditional oilfield chemical supply model of direct no-return sales. The ecological part of the study looked at the life-cycle inventory of the products, recording all relevant emissions, material and energy flows through the product's life cycle, and a complete life-cycle assessment. The economic part of the study used the total cost of ownership cost calculation provided by Gaia Consulting, including all costs attached to product use, such as energy, maintenance and environmental protection costs.

Surprisingly, CSF is still the only oilfield chemical supplier using the Chemical Leasing business model, whereas the rest of the chemical suppliers are opting to stick with traditional no-return sales and transfer of ownership.

\subsection{Winner Case Safechem Europe GmbH and Partner Pero AG}

Industrial process: industrial cleaning with solvents.

Following its mission "We are the Service Company Responsible for the Sustainable and Innovative Use of Chemicals" SAFECHEM Europe GmbH, a global business unit of The Dow Chemical Company, has since its foundation been focusing on providing sustainable solutions for industrial surface cleaning with solvents, following the cradle to cradle philosophy. SAFECHEM is not only the inventor of closed loop safety systems (SAFE-TAINER $^{\mathrm{TM}}$ ) for safe delivery, take-back and handling of hazardous solvents but has also constantly extended its service offerings allowing customers to run solvents for cleaning in closed loops with minimized solvent consumptions and highest cleaning results. Building partnerships and cooperation with major cleaning equipment producers is an essential element of the business. SAFECHEM naturally has become a pioneer in the development and constant improvement of chemical product service business models. It was one of the first to participate in the shaping of the Chemical Leasing Concept as initiated, guided and sponsored by the Austrian
Ministry of the Environment.

In 2005, SAFECHEM Europe GmbH combined efforts with PERO AG Königsbrunn and its daughter company Pero Innovative Services as Chemical Leasing partners to launch the first Chemical Leasing (CL) case for surface cleaning with Blau Automobiltechnik, a daughter company of MAGNA STEYR, as leasing client. The specific model set-up for this case includes leasing of latest technology equipment and process operation. SAFECHEM is acting as the chemical product and know-how supplier providing the cleaning solvent in the closed loop SAFE-TAINER system, technology and know-how to monitor and re-adjust the solvent quality, training of partners and clients and provisions on safe waste takeback and waste management. Pero is proving the latest technology cleaning machine and the know-how to run the equipment in an optimum way. Pero Innovative Services finally is running the cleaning process for the client, based on the combined know-how of SAFECHEM and Pero. Pricing unit is the number of parts cleaned with different unit prices for different parts according to their cleaning complexity.

Within 4 years, in which the case model has been running, it has fully satisfied expectations. The case has demonstrated to be able to generate beside the environmental benefits the cost savings needed to be economically beneficial for all participants also in the context of technically advanced countries. Solvent emission reduction is well over $90 \%$, the solvent consumption was reduced by $72 \%$ and the need for stabilizers by over $55 \%$. In addition to that a reduction in energy consumption of $50 \%$ could be achieved. These high reduction rates were possible because latest technology equipment is provided to the lessee and the process is fully run by a lessor partner. For cases, where the equipment leasing and/or process operation is not part of the Chemical Leasing model, lower solvent consumption savings (> 50\%) are projected.

Beside these short term benefits, a long-term benefit, judged very important by SAFECHEM, is to make solvents sustainable and to assure their long-term availability. This not only benefits clients by giving them assurance to achieve the quality required for the continuous improvement of their products. It also benefits the chemical producer/supplier by allowing him to achieve a high value with his products, although they are used in minimized quantities and to contribute in this way to the progress of mankind as well as to the preservation of the environment and of human health. Based on the "Austrian” case results, SAFECHEM decided to make Chemical Leasing an integral part of a business growth strategy and has agreed with partners to start implementation of further cases throughout Europe. To facilitate implementation, SAFECHEM will focus in a first step on the 
conversion from selling to leasing the chemical product service solutions. Extending the offer to include equipment leasing, as in the Austrian case, will follow in a further step.

\subsection{Special Award for Outstanding Efforts in Implementing Chemical Leasing in the Supply Chain was Given to IKEA Trading (HK) Ltd., India [5,6]}

Industrial process: the scope of the project was focused on the textile dyeing process in India.

The IKEA Trading Office in India facilitated the implementation of the project with its suppliers in its supply chain. The identified partner in this project was Ciba, later called Huntsman, because of their dyes and chemicals portfolio, their technical competency and visionary leadership.

IKEA has declared in its latest Sustainability Report, 2009 that:

"IKEA helps selected IKEA textile suppliers to connect with chemical suppliers in a service-based model referred to as "Chemical Leasing" in order to reduce the use of chemicals in manufacturing. This method is adapted from the car industry, and involves a technical specialist from the chemical supplier being placed at the textile supplier. The specialist is assigned to oversee the processing and to support better chemical, energy and water management. In the years 2005-09, suppliers in India reduced their use of chemicals significantly as well as their water and energy use. Several suppliers increased their capacity during the same period.”

The Chemical Leasing project was implemented from 2005-09 with defined scope in time, space, material, and deliverables. The projects were implemented for periods ranging from 6 months to two years. The projects were allowed 'cooling off' periods when the business situation demanded.

Huntsman took over the responsibility for the entire wet processing in the supplier's factory that included pre-treatment, bleaching, dyeing and finishing processes. Most of the dyes and chemicals used were from Huntsman itself; however some competitor products were used as well.

Chemical Leasing has supported the IKEA supply chain towards team building, process optimization, laboratory management, inventory management, safety data sheets, chemical compatibility, reduction in hazards, use of personal protective equipments, good house keeping, risk management and pollution prevention. Right-FirstTime (meaning no re-dyeing) improved immensely in the project period. Boiler and machine maintenance was streamlined and maintenance costs decreased. Chemical
Leasing ensured the compliance with the EU REACH Directive in a simple and efficient way. Huntsman trained the factory workers on operations controls, environmental, occupational health and safety issues.

The functional unit of payment was easy to define for the yarn dyeing units in terms of Rupees/kg of yarn dyed. The difficult issue was to agree on different payments for different colours. The project team finally settled on differential payments for different functionalities of dark, medium and light colours and bleached products.

\section{Conclusions}

Chemical Leasing is a novel service-based business model that supports sustainable chemicals management and responds to some of the latest changes in international chemical policies. It encourages progressive and environmentally sound business and the outlined examples demonstrate how this model can help participating companies to reduce ineffective use and over-consumption of chemicals, save costs, and improve working conditions.

In many cases $\mathrm{ChL}$ also supports the development of a strong long-term business partnership that advances process improvement and technology innovation. The business model also showed remarkable results if applied to processes that are not related to the core expertise of the chemicals user and the main production process, e.g. cleaning, coating.

This business model represents a shift of paradigm as it allows for profitable business activities while decoupling economic success from product turnover. It is therefore one of the rare examples where resource efficiency in the application of products (in that case chemical products) is becoming an asset even for the producers themselves.

Challenges related to Chemical Leasing are trust building between participating companies and the resistance to shift the focus from increasing sales volume of chemicals towards a value-added approach.

Sustainability criteria are currently being developed and globally tested to protect the positive image of Chemical Leasing and to prevent the misuse of the term Chemical Leasing e.g. for non-adequate activities related to health or the environment. In addition, the criteria also provide guidance for the implementation of successful ChL business cases with continuous improvement for environment and health resulting from reduced impacts by chemicals and machinery and improved handling of chemicals regarding risk prevention/reduction.

\section{References}

[1] T. Jakl and P. Schwager, “Chemical Leasing Goes Global 
- Selling Services Instead of Barrels: A Win-Win Business Model for Environment and Industry,” Springer, Wien, New York, 2008.

[2] Chemical Leasing Annual Report, Lebensministerium \& UNIDO, Vienna, 2009. Internet Available: http://www.chemicalleasing.com

[3] UNIDO, “Austrian Ministry Launch Global Award for Chemical Leasing,” 2009.
[4] IKEA Sustainability Report, 2008 \& 2009.

[5] A. Priyadarshi, the Colourist, Vol. 1, No. 4, 2009, p. 8.

[6] A. Priyadarshi, "Chemical Leasing in Colour and Environmental Management - Theoretical Framework, Implementation Methodology and Future Outlook,” Paper Presented at UNIDO - GCPC Chemical Leasing Workshop, 2009. 